Article

\title{
Estimation of Extreme Loads of the Mi-24 Helicopter During Maneuvers Using Simulation Method
}

\author{
Grzegorz Kowaleczko ${ }^{1}$, Lukasz Piatkowski ${ }^{2}$ \\ 1 Military University of Aviation, Poland; grzegorz.kowaleczko@itwl.pl (PL) \\ 2 Air Force Institute of Technology, Poland; lukasz.piatkowski@itwl.pl \\ * Correspondence: grzegorz.kowaleczko@itwl.pl
}

\begin{abstract}
The aim of the study is to assess the loads that are transferred from the main rotor and the tail rotor to the helicopter fuselage. These loads change in the various phases of the transient flight as a result of the variable control of the maneuver and as a result of the variable flow around the blades. The knowledge of the loads allows for the proper selection of the level of excitations that should load the fuselage structure during fatigue and strength tests. The simulation model describing the helicopter flight is discussed. This model takes into account the motion of each blade relative to its hinges. Results are shown for two maneuvers - pullup/pushover and diving. The values of extreme loads transferred to the fuselage were obtained.
\end{abstract}

Keywords: helicopter loads; fatigue and strength tests; pullup/pushover and diving maneuvers

\section{Introduction}

The issue of assessing the loads arising during a helicopter flight is the subject of experimental and theoretical research. Their results are the basis for design decisions and have an impact on the safe operation of helicopters. Especially many publications are theoretical. Where possible, calculation results are compared with flight test data. Flight tests are expensive and their results are often unpublished and owned by helicopter companies. On the other hand, theoretical analyzes are based on computational models of varying complexity. Due to the various aerodynamic effects affecting the forces and moments produced by the main rotor, calculation models are often simplified. The simplifications concern both the aerodynamics of the main rotor blades and the analyzed flight states. Most often they are limited to the analysis of the aerodynamic loads of the rotor blades.

A frequently used mathematical model is the blade element model. It can be found both in classic books on helicopters [1-3] and in articles, for example [4-6].

As a first approximation, the blade is assumed to be rigid. More complex analyzes take into account its aeroelasticity. [7] discusses the results of calculations of local blade loads using the UMARC Helicopter Aeroelactic Code for the OH-58 Kiowa Warrior. The rotor blades were treated as "an elastic beam undergoing flap bending, lag bending, elastic twist, and axial deflections". The helicopter fuselage was taken as a rigid body with 6-DOF. The calculations were made for hover and forward flight conditions. To verify the analytical model, the calculated loads were compared with flight data for the Bell model 
406LM helicopter. In [4] the equations of motion of the deformable blade were solved by applying Galerkin's method. The results of calculations were presented in the form of plots showing the time-run of the loads and the distributions of deformations due to the blade azimuth position on the rotor disk. The results of the simulation give useful data to create a spectrum of variable loads generated by the rotor.

When calculating the load on the rotor blades, numerical methods of fluid mechanics are also used. Such methods were applied to calculate the loads on the Mi-8 helicopter blades. It was described in the publication [8]. Strength analysis of glued joints between metal and composite trailing edge segments was also performed. Similarly, in the doctoral dissertation [9], the estimation of aerodynamic loads on the rotor blades in forward flight was analyzed by solving the linearized flow equations.

An important issue is the assessment of the influence of non-stationary effects on the aerodynamic load on the blades. The work [10] comes from 1964, in which the theoretical possibility of solving this problem was discussed. On the other hand, [11] shows the results of measurements of the lift force and the tilting moment of the blade sections made in a wind tunnel.

The modeling of the vortex system behind the rotor is also extremely important. These vortices have an impact on the local angle of attack of the blade sections, and thus on the local aerodynamic loads. A description of this problem can be found in books, e.g. [1-3]. Application examples are shown in [10] and [12].

As said before flight tests are expensive, often unpublished, and owned by helicopter companies. They require specialized equipment and overcome many difficulties. Due to the safety rules, hover, level flight, or gentle maneuvers are usually performed. For example, [13] presents the results of flight tests for two helicopters - NH-3A and CH-53A. The measurements allowed, among other things, to assess the changes in the three orthogonal hinge forces, nonrotating hub loads, and section loads of blades (forces and moments). The tests were carried out for trimmed level flight, transition, and steady-state coordinated banked turns. The influence of various factors was investigated - effects of airspeed, effects of maneuvers, effects of blad/tip-vortex interactions, effects of blade bending, effects of aerodynamic pitching moments.

The safety limits must not be exceeded during the flight tests. Therefore, knowledge about loads generated in extreme flight conditions is limited. In this situation, a theoretical estimate of these loads may be useful. The developed software can be applied to predict the limits of a helicopter flight envelope and to avoid potentially dangerous conditions of flight.

Combat helicopters are subjected during their operation to considerable loads exceeding those for civilian helicopters. The values of these loads result from the necessity to perform maneuvering flights with high dynamics. The resulting loads have a direct impact on the service life of military helicopters. Further operation is possible under the condition of performing a series of tests and examinations confirming the preservation of the endurance properties by the force elements of the helicopter.

Mi-24 helicopters have been used in the Polish armed forces for many years. To assess the possibility of their further use, tests are currently carried out consisting in 
carrying out strength tests of the Mi-24 helicopter. It is necessary to know the range of loads arising during flight. These loads will be mapped during the tests on the test stand. It should be taken into account that the main and tail rotors are the source of the highest loads transferred to the fuselage.

To assess the loads generated during the flight, numerical simulations and flight measurements with the use of strain gauges are performed simultaneously. For the first purpose, the mathematical model of the helicopter was used, which allows the simultaneous simulation of the helicopter's motion in space and the motion of each rotor blade about the hinges. This model was originally developed by researching the Polish W3 Sokol helicopter [14-16]. Using it, the previously performed maneuvers were recreated and the behavior of the helicopter in the planned maneuvers was also forecasted [17]. For this purpose, software was developed to solve the problem of inverse dynamics [18, 19]. Simulations were also carried out on the ground resonance [20] and the flutter of the helicopter blades [21]. This model was also used to analyze the impact of various types of blade failures on helicopter flight dynamics [22].

To make calculations for the Mi-24 helicopter, the simulation model was modified the geometry and mass characteristics of the helicopter and the different number of main rotor blades were taken into account. Geometric and mass data were obtained based on the technical descriptions of the helicopter [23-26] and in many cases through measurements and engineering calculations. Other aerodynamic characteristics of the helicopter and the characteristics of the control system were also taken into account.

\section{Formulation of the Problem}

The model used for simulations assumes that the helicopter fuselage is a rigid body with 6 degrees of freedom. Each of the main rotor blades is rigid and oscillating with respect to the horizontal hinge (flapping) and the vertical hinge (lagging). Motion about and the axle hinge (feathering) is due to control inputs and compensation of flapping motion. The tail rotor is treated as a hingeless and weightless source of thrust which equilibrates the torque moment of the main rotor and ensures directional control of the helicopter. Figure 1 shows the coordinate systems and the angles between them used to describe the motion of the helicopter.

Finally, a system of equations was obtained, which includes:

- $\quad$ vector equation of translatory motion of the helicopter (3 scalar equations);

- vector equation of equilibrium of moments about the center of mass of the fuselage (3 scalar equations);

- $\quad$ equation describing the rotation of the main rotor about the axis of the hub;

- $\quad$ equation of equilibrium of moments of external forces acting on each blade about its flapping hinge $P_{H}$;

- the equation of equilibrium of moments of external forces acting on each blade about its lagging hinge $P_{V}$;

- the kinematic relations.

This system consists of 34 nonlinear differential equations with periodic coefficients. The final form of this set has the following form:

$$
\boldsymbol{A}(t, \boldsymbol{X}) \dot{\boldsymbol{X}}+\boldsymbol{B}(t, \boldsymbol{X})=\boldsymbol{f}(t, \boldsymbol{X}, \boldsymbol{S})
$$

where $X$ is the vector of flight parameters:

$$
\boldsymbol{X}=\left(U, V, W, P, Q, R, \omega, \dot{\beta}_{i}, \dot{\zeta}_{i}, \beta_{i}, \zeta_{i}, \psi, \Theta, \Phi, \Psi, x_{g}, y_{g}, z_{g}\right)^{T}
$$


$U, V, W$ - linear velocities of the center of the fuselage in the system $O x_{k} y_{k} z_{k}$ fixed with the fuselage,

$P, Q, R$ - angular velocities of the fuselage in the same coordinate system (rolling, pitching, yawing),

$\Theta, \Phi, \Psi$ - pitch, bank and yaw angles of the fuselage,

$\beta_{i}$ - $i$-th blade flapping angle about the horizontal hinge $P_{H}$,

$\zeta_{i}$ - $i$-th blade lagging angle about the vertical hinge $P_{V}$,

$\omega$ - the angular velocity of the main rotor,

$\psi$ - the azimuth of the main rotor.

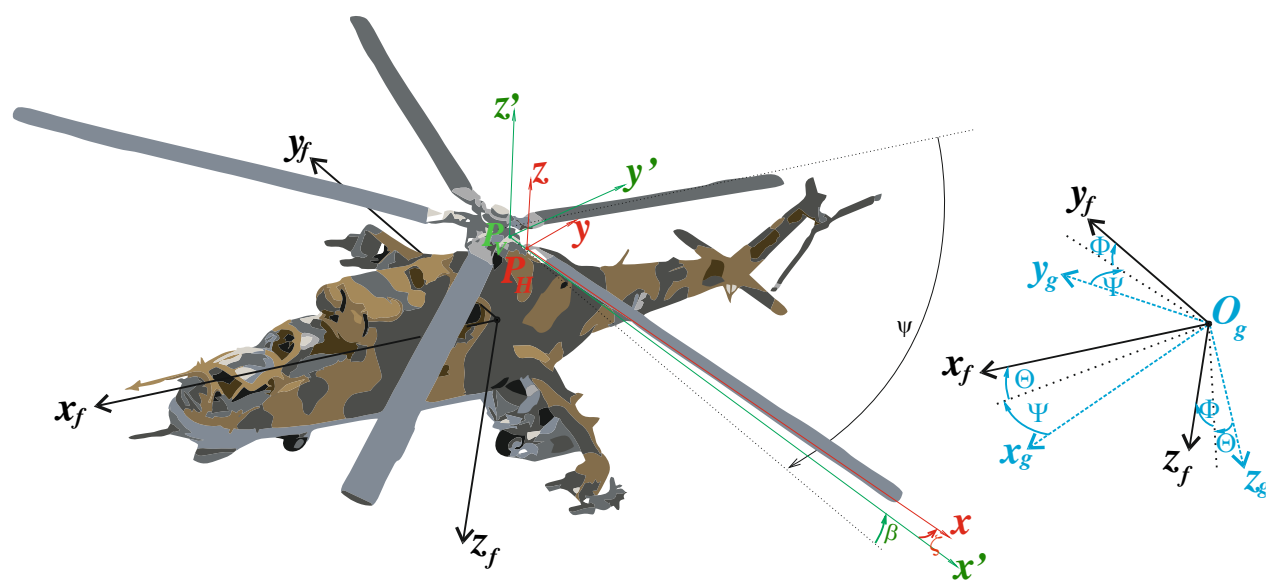

Figure 1. Physical model of the helicopter and coordinate systems

Vector $S$ is the control vector:

$$
\boldsymbol{S}=\left(\theta_{0}, \theta_{\mathrm{sin}}, \theta_{\mathrm{cos}}, \varphi_{t r}\right)^{T}
$$

where: $\theta_{0}$ is the angle of collective pitch of the main rotor; $\theta_{\cos }$, and $\theta_{\sin }$ are cyclic pitch

angles of the swashplate; $\varphi_{t r}$ is the angle of the collective pitch of the tail rotor.

To determine the matrix $\boldsymbol{A}$ and the vector $\boldsymbol{B}$ in (1) there were successively established: the locations of all helicopter elements, the absolute velocities of these elements, and their absolute accelerations.

The vector $\boldsymbol{f}(t, \boldsymbol{X}, \boldsymbol{S})$ in (1) symbolizes external forces and moments acting on a helicopter and on its parts and also represents the right-hand sides of kinematic relations. These forces and moments may be divided into two groups: - the aerodynamic forces and moments, - the gravitation forces, and moments.

The aerodynamic forces and moments acting on the rotor blades were determined by making use of static characteristics of airfoils of Mi-24 helicopter blades in the full range of angle-of-attack for different Mach numbers [2]. This allowed taking into account the specific conditions of airflow around the blades, including the reverse flow zone. As the critical angle of attack is dynamically exceeded during blade motion, especially at high airspeeds, the dynamic stall effects were also modeled using Tarzanin's method [27, 28]. The effect of spanwise (radial) flow on the lift coefficient was also taken into account. The induced velocity of each airfoil was calculated using Biot-Savart law - five separated 
strings of the vortex generated by blades were investigated. All aerodynamic forces and moments acting on blades were calculated by numerical integration along each blade. Aerodynamic forces and moments acting on the fuselage were determined using its aerodynamic characteristics [26].

\section{Results}

The calculations were made for two helicopter maneuvers - pullup/pushover and diving. Modeling was based on helicopter data [23-26]. There you can find data on how to perform maneuvers and data on operational limitations. Among other things, it includes the limit values of some parameters, the exceeding of which is not allowed. Sample data for the pullup/pushover maneuver are given in Table 2, and for the diving maneuver in Tables 3 and 4 .

Table 2. Pullup/pushover maneuver parameters

\begin{tabular}{|c|c|c|c|c|c|c|}
\hline \multirow{3}{*}{$\begin{array}{c}\text { Parameter } \\
\text { angle change [deg] }\end{array}$} & \multicolumn{6}{|c|}{ Initial velocity $[\mathrm{km} / \mathrm{h}]$} \\
\hline & \multicolumn{3}{|c|}{250} & \multicolumn{3}{|c|}{$280 \div 300$} \\
\hline & 10 & 20 & 30 & 10 & 20 & 30 \\
\hline Altitude increment [m] & 400 & 260 & 240 & 90 & 500 & 400 \\
\hline Time of the maneuver [s] & 40 & 20 & 14 & 70 & 30 & 20 \\
\hline Permissible vertical overload & \multicolumn{3}{|c|}{$\begin{array}{l}1.6 \text { for altitude up to } 500 \mathrm{~m} \\
1.5 \text { for altitude up to } 500-1000 \mathrm{~m}\end{array}$} & \multicolumn{3}{|c|}{1.3 for altitude up to $500 \mathrm{~m}$} \\
\hline
\end{tabular}

Table 3. Diving maneuver parameters

\begin{tabular}{|c|c|c|c|c|c|}
\hline \multirow{2}{*}{$\begin{array}{c}\text { Barometric flight } \\
\text { altitude }[\mathrm{m}]\end{array}$} & \multicolumn{5}{|c|}{ Maximum dive angles when introduced diving at different velocities } \\
\cline { 2 - 6 } & $100 \mathrm{~km} / \mathrm{h}$ & $150 \mathrm{~km} / \mathrm{h}$ & $200 \mathrm{~km} / \mathrm{h}$ & $250 \mathrm{~km} / \mathrm{h}$ & $270 \mathrm{~km} / \mathrm{h}$ \\
\hline up to 500 & $30^{0}$ & $30^{0}$ & $20^{0}$ & $10^{0}$ & $5^{0}$ \\
\hline $500 \div 1000$ & $30^{0}$ & $25^{0}$ & $15^{0}$ & $5^{0}$ & - \\
\hline $1000 \div 2000$ & $30^{0}$ & $20^{0}$ & $5^{0}$ & - & - \\
\hline $2000 \div 3000$ & $30^{0}$ & $15^{0}$ & $5^{0}$ & - & - \\
\hline
\end{tabular}

Table 4. Diving maneuver parameters

\begin{tabular}{|c|c|c|c|}
\hline $\begin{array}{c}\text { Barometric flight } \\
\text { altitude [m] }\end{array}$ & \multicolumn{2}{|}{$\begin{array}{r}\text { Maximum final velocity for the diving maneuver } \\
\text { depending on the value of diving angles }\end{array}$} \\
\cline { 2 - 4 } & up to $10^{0}$ & $10^{0} \div 20^{0}$ & $20^{0} \div 30^{0}$ \\
\hline up to 1000 & $290 \mathrm{~km} / \mathrm{h}$ & $280 \mathrm{~km} / \mathrm{h}$ & $270 \mathrm{~km} / \mathrm{h}$ \\
\hline $1000 \div 2000$ & $260 \mathrm{~km} / \mathrm{h}$ & $250 \mathrm{~km} / \mathrm{h}$ & $240 \mathrm{~km} / \mathrm{h}$ \\
\hline $2000 \div 3000$ & $220 \mathrm{~km} / \mathrm{h}$ & $210 \mathrm{~km} / \mathrm{h}$ & - \\
\hline
\end{tabular}

The analysis of the data from the tables allowed for the development of a simulation scenario that was used in the calculations. Since the purpose of the simulation was to determine the maximum loads that may occur during the maneuver, simulation data were adopted to obtain values of flight parameters close to their maximum permissible values.

Both analyzed maneuvers should be carried out by proper pitching up and down of the fuselage. This motion was modeled by applying appropriate constraints to it, which 
was to be performed by the autopilot. The runs of constraints are shown further in the figures, which present the change of the pitching angular velocity $Q(t)$. Both maneuvers should be performed in the vertical plane without a bank or yaw. These are the next constraints imposed on the motion of the helicopter. The control signals were calculated using the so-called inverse dynamics. The method of their calculation has been discussed in other publications [ 18,19$]$.

The weight of the helicopter was $11500 \mathrm{~kg}$. For both maneuvers, the first five seconds of simulation are for steady-level flight. This assumption makes it possible to check whether the initial conditions relating to the established level flight are correctly determined and whether the autopilot maintains them effectively. Therefore, it was assumed that the maneuver starts at the 5th second of the simulation.

In particular, it was taken into account that:

- for the pullup/pushover maneuver:

The maneuver begins with a horizontal flight at two airspeeds of $260 \mathrm{~km} / \mathrm{h}$ and 300 $\mathrm{km} / \mathrm{h}$. During the maneuver, the flight path angle should reach a value close to $30^{\circ}$. The maneuver is performed in 20 seconds with a constant collective pitch of the main rotor. The final velocity should not be lower than $120 \div 100 \mathrm{~km} / \mathrm{h}(33.33 \div 27.78 \mathrm{~m} / \mathrm{s})$.

- $\quad$ for the diving maneuver:

The maneuver starts with a horizontal flight performed at two speeds of $140 \mathrm{~km} / \mathrm{h}$ and $260 \mathrm{~km} / \mathrm{h}$. During the maneuver, the flight path angle should reach a value close to $-30^{\circ}$. The maneuver is performed in 20 seconds with a constant collective pitch of the main rotor.

Figure 2 shows the forces and moments that were calculated during the simulation. Their positive directions coincident with the fuselage system axes $O x_{f} y_{f} z_{f}$ are marked. They formed the basis for the assessment of the maximum loads transferred from the main rotor and tail rotor to the helicopter fuselage. The results for the pullup/pushover maneuver will be shown in detail below. The diving maneuver is limited to presenting only the courses of forces and moments generated by the main rotor and the tail motor.
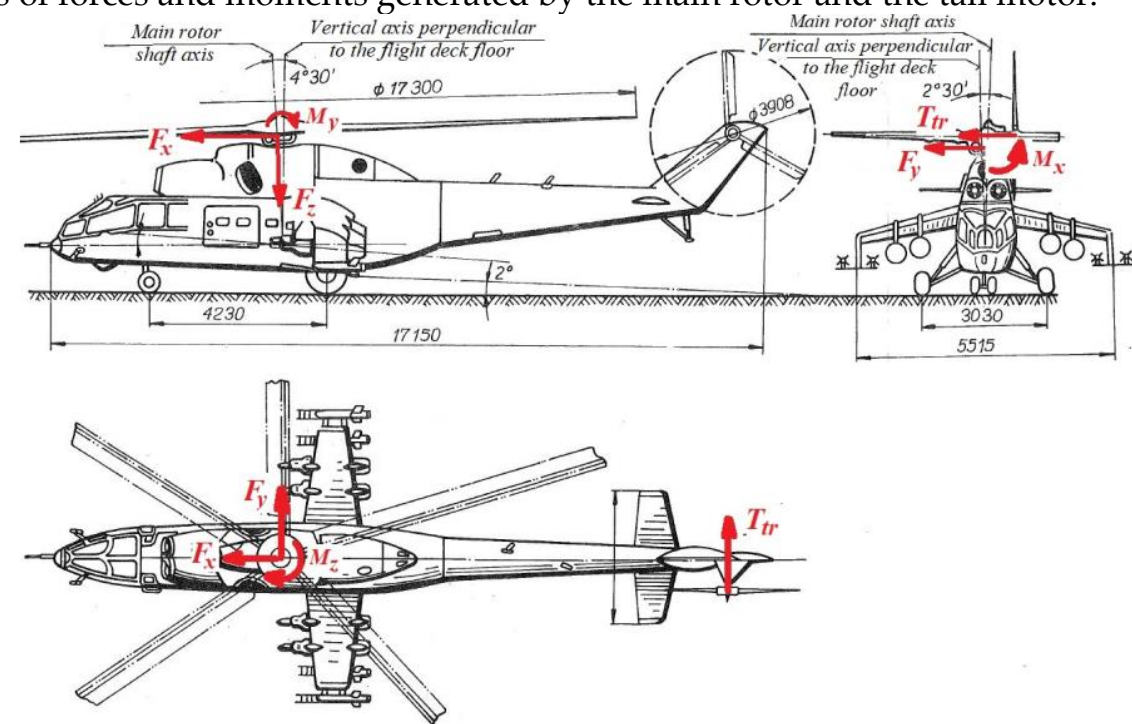

Figure 2. Scheme of calculated loads 


\subsection{Pullup/pushover maneuver}

Figures $3 \div 20$ present the obtained flight parameters. These drawings show that:

- Fig. 3 - the final velocity of the maneuver is within the assumed range $33.33 \div 27.78$ $\mathrm{m} / \mathrm{s}$;

- Fig. 4 - the altitude increment is within the range of $250 \div 350$ meters;

- Fig.5 - the profile of pitching angular velocity corresponds to the assumed constraints, but differs in the values obtained;

- Fig. 6 - the pitch angle reaches $25^{\circ} \div 30^{\circ}$;

- Fig.7 - the angle of the flight path reaches the value of $30^{\circ} \div 35^{0}$, which is close to the limitation imposed on the maneuver;

- Fig.8 - during the maneuver, a variable bank appears which should be compensated by the pilot;

- Figs.9 $\div 11$ - the collective pitch angle is invariant (as assumed), and cyclic controls are the result of the implementation of the appropriate control laws;

- Figs. 12,13 - during the maneuver, all blades oscillate intensively about both hinges, but their range does not exceed the operational values;

- Fig.14 - in steady flight, the longitudinal force acts in the rear and has a value of about $270 \mathrm{kG}$. In the first phase of the maneuver, this value increases to about 800 $\mathrm{kG}$ (backward), and during pushover, it reaches $400 \div 500 \mathrm{~kg}$ (forwards) ;

- Fig. 15 - in steady flight, the side force is $250 \div 350 \mathrm{kG}$ (to the right). During the maneuver, this value increases to $500 \mathrm{kG}$ for the initial speed of $300 \mathrm{~km} / \mathrm{h}$;

- Fig.16 - the vertical force (along the hub axis) in steady flight is about $9500 \mathrm{kG}$ (up). During the maneuver, its maximum value reaches $14000 \mathrm{kG}$;

- Fig.17 - during level flight, the rolling moment amounts to $200 \div 300 \mathrm{kGm}$ (roll to the right). During the maneuver, it changes direction. In the final stage it reaches the value of $400 \div 500 \mathrm{kGm}$;

- Fig.18 - in steady flight, the pitching moment (pitch up) of $450 \mathrm{kGm}$ is transferred to the hub. This moment changes significantly during the maneuver, reaching the values of $950 \div 1200 \mathrm{kGm}$ (for pitching up) and $700 \div 1000 \mathrm{kGm}$ (for pitching down).

- Fig.19 - the yawing moment transmitted to the fuselage depends significantly on the flight speed. Its maximum value does not exceed $10000 \mathrm{kGm}$;

- Fig.20 - the tail rotor thrust depends significantly on the flight speed. In steady flight, its maximum value is equal to $650 \mathrm{kG}$ (to the left). Its value in the maneuver reaches $800 \mathrm{kG}$ (to the left);

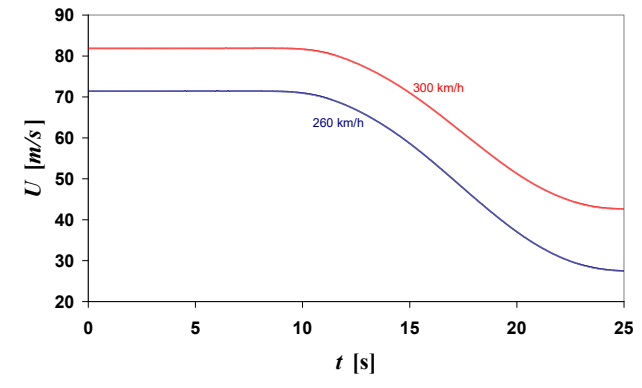

Figure 3. Helicopter flight velocity

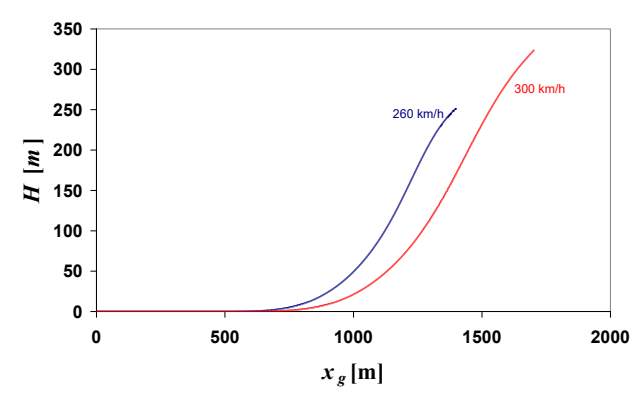

Figure 4. Vertical trajectory 


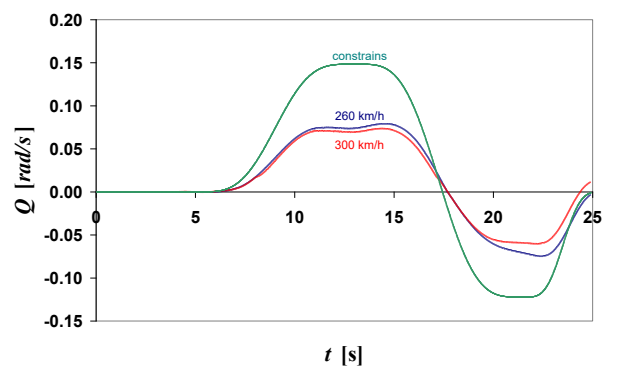

Figure 5. Pitching angular velocity

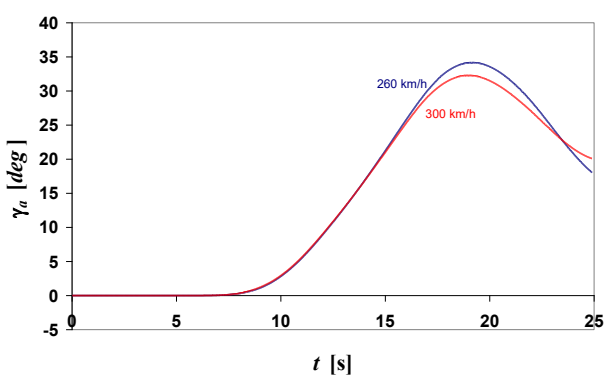

Figure 7. Flightpath angle

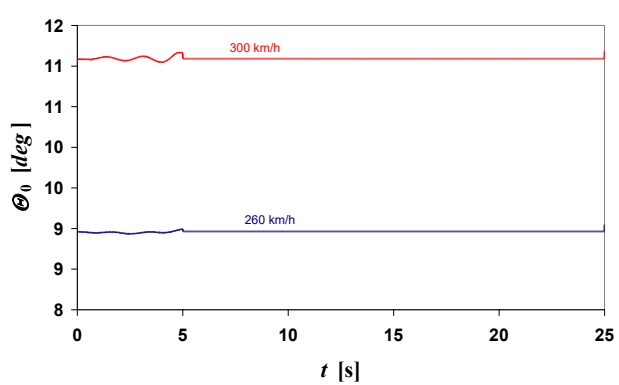

Figure 9. Collective pitch angle (control input)

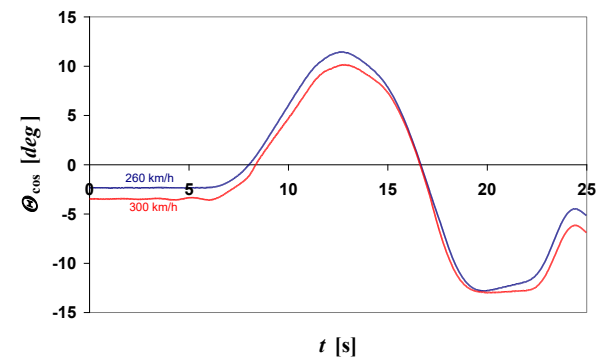

Figure 11. Cyclic pitch angle (control input)

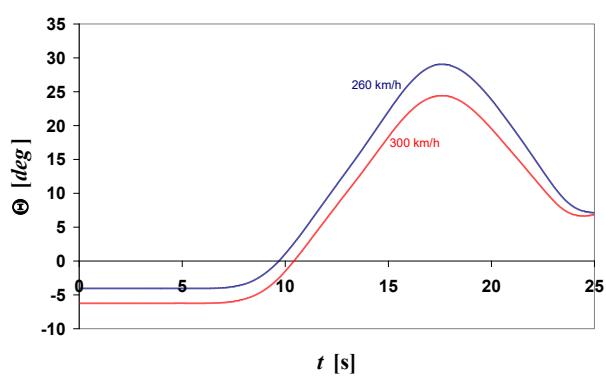

Figure 6. Pitch angle

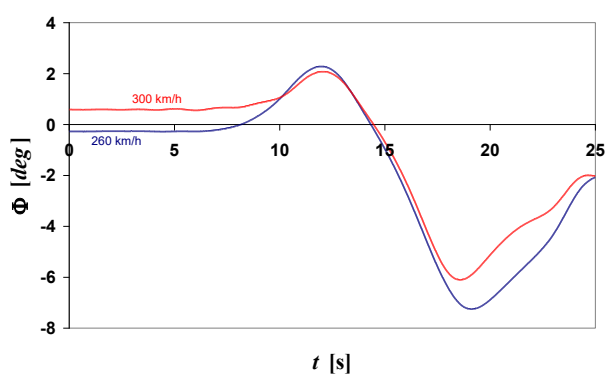

Figure 8. Bank angle

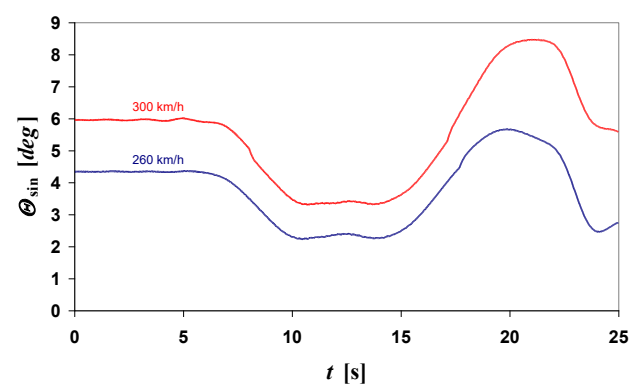

Figure 10. Cyclic pitch angle (control input)

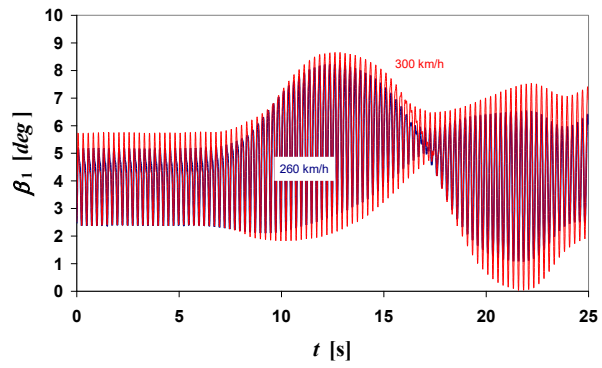

Figure 12. Flapping of blade No.1 


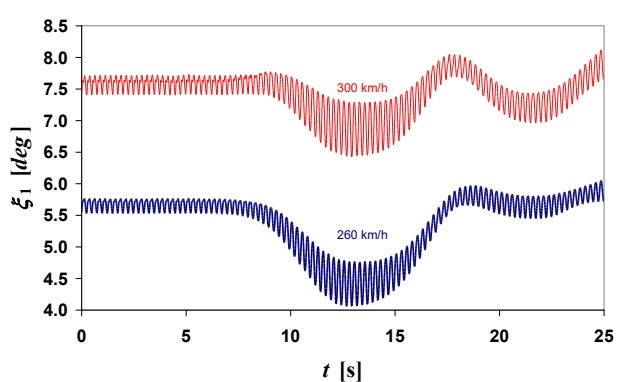

Figure 13. Lagging of blade No.1

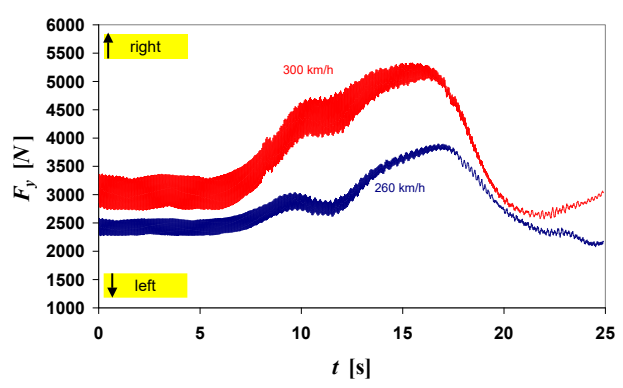

Figure 15. Side force transferred from the main rotor

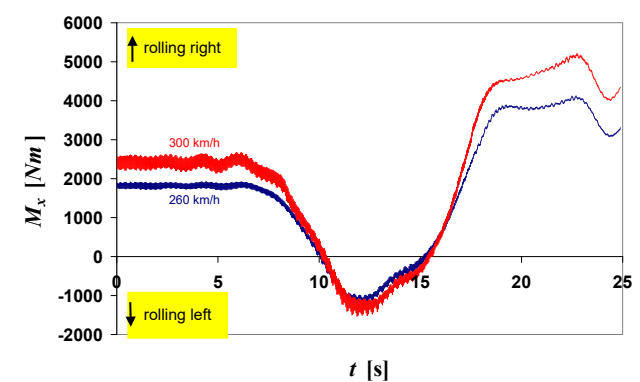

Figure 17. Rolling moment transferred from the main rotor

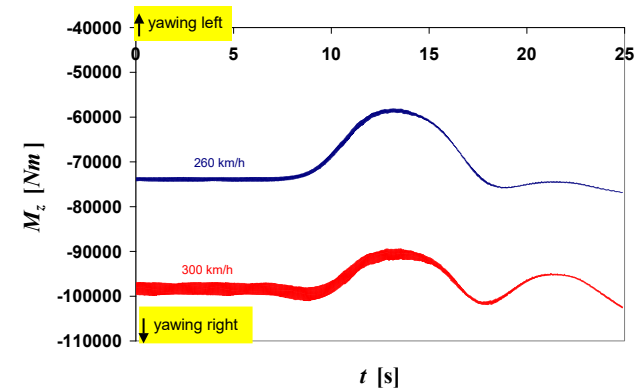

Figure 19. Yawing moment transferred from the main rotor

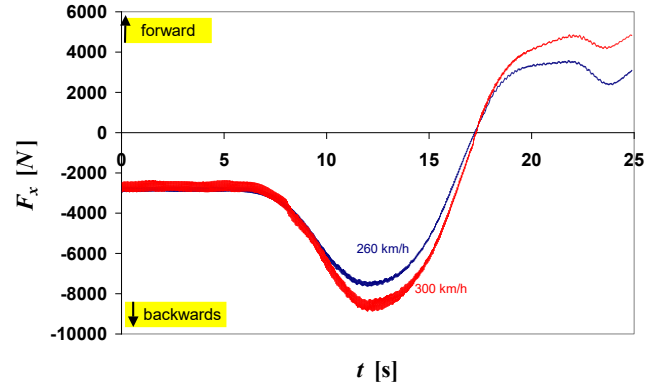

Figure 14. Longitudinal force transferred from the main rotor

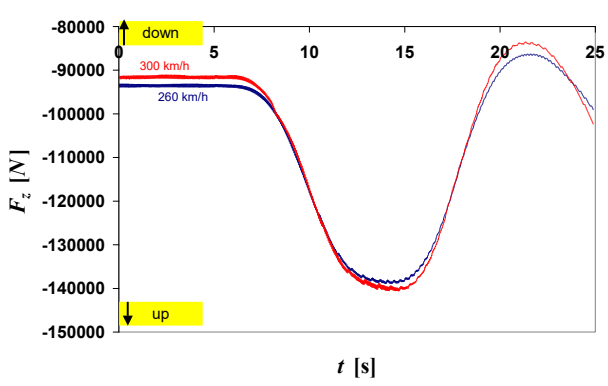

Figure 16. Vertical force transferred from the main rotor

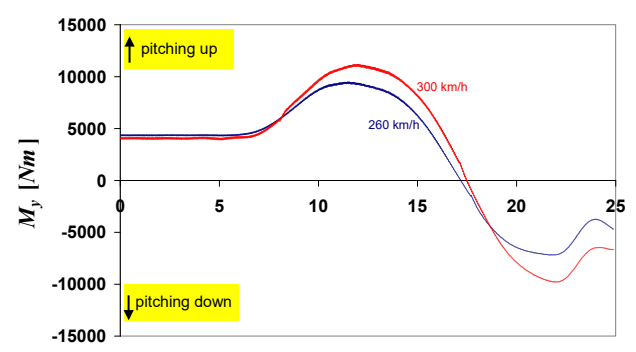

$t[\mathrm{~s}]$

Figure 18. Pitching moment transferred from the main rotor

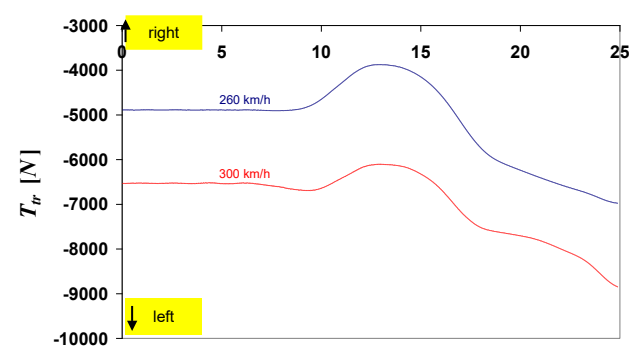

$t[\mathrm{~s}]$

Figure 20. Thrust of the tail rotor 


\subsection{Diving maneuver}

During simulated diving, the speed increases by about $15 \div 20 \mathrm{~m} / \mathrm{s}$ and the altitude decrease by about 130 $\div 80$ meters. The pitch angle of the helicopter initially decreases by about $15^{0} \div 19^{0}$ and then increases to the value close to the initial value. Due to the feedback, slight changes in the bank angle are observed (about $4^{0}$ to the right). When pulling up from dive, the blades oscillate significantly about the horizontal hinge. Figures $21 \div 27$ show the forces and moments transferred from the main rotor and from the tail rotor to the fuselage.

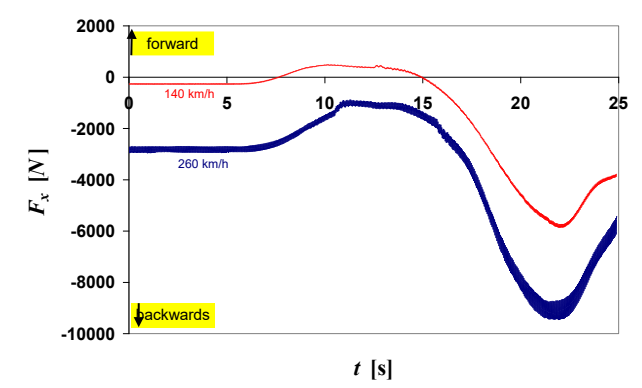

Figure 21. Longitudinal force transferred from the main rotor

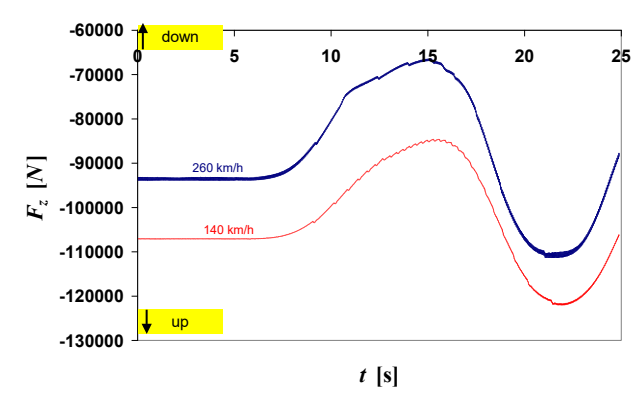

Figure 23. Vertical force transferred from the main rotor

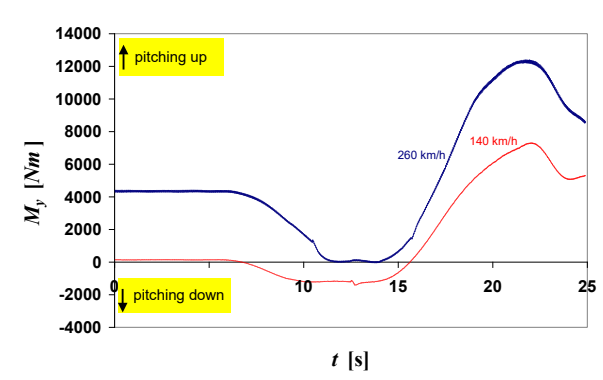

Figure 25. Pitching moment transferred from the main rotor

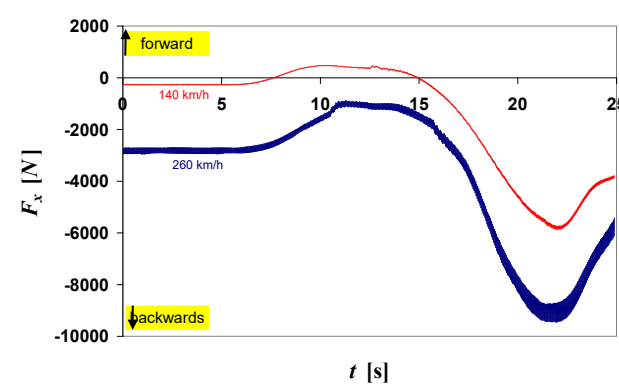

Figure 22. Side force transferred from the main rotor

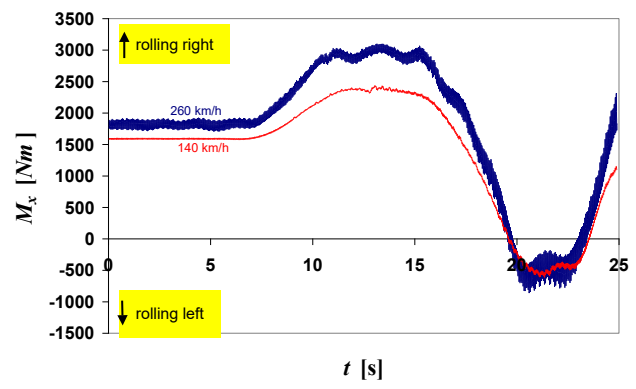

Figure 24. Rolling moment transferred from the main rotor

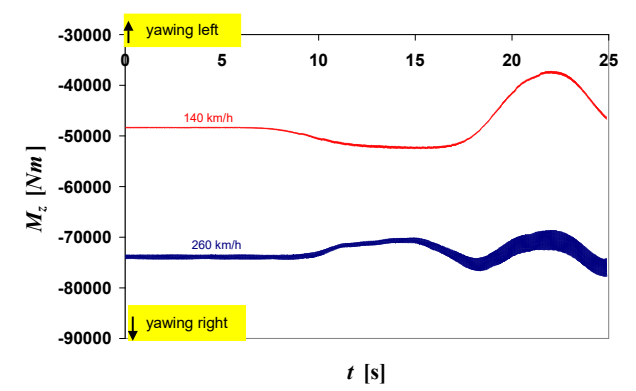

Figure 26. Yawing moment transferred from the main rotor 


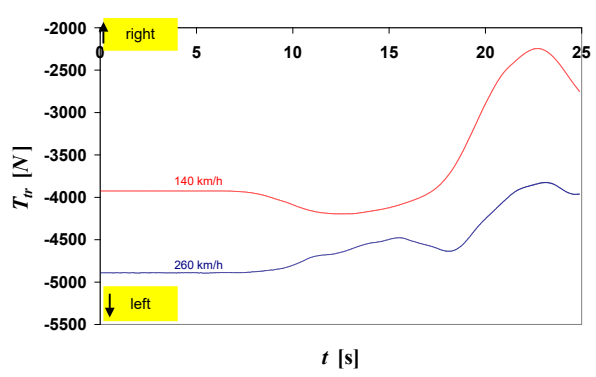

Figure 27. The thrust of the tail rotor

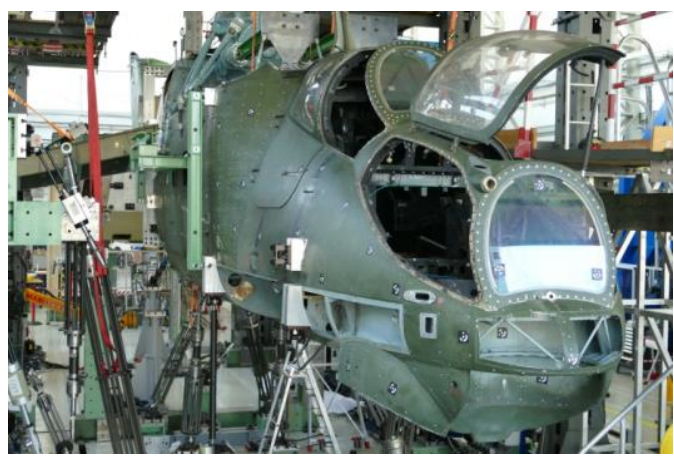

Figure 28. Helicopter on the test stand

\subsection{Results Summary}

Analyzes of loads courses transferred from the main rotor and the tail rotor to the fuselage allow you to determine their extreme values. As the scenario of the analyzed maneuvers took into account the maximum allowable airspeeds and flight parameters, it can be assumed that the load values are equal to the maximum loads that occur during the flight. These extreme loads are collected in Table 5. They can be an indication of loading the helicopter structure on the test stand shown in Figure 28. The determined ranges of load changes allow for the proper fatigue and strength tests preparation.

It should be remembered that the obtained simulation results can be treated only as an approximation of the real loads occurring during the flight. Therefore, they are complemented by measurements made during test flights. Such flights are currently carried out by the research team.

Table 5. Extreme loads transmitted to the fuselage

\begin{tabular}{|l|c|c|c|c|c|c|c|}
\hline Forces/moments & $\begin{array}{c}F_{x} \\
{[\mathrm{kG}]}\end{array}$ & $\begin{array}{c}F_{y} \\
{[\mathrm{kG}]}\end{array}$ & $\begin{array}{c}F_{z} \\
{[\mathrm{kG}]}\end{array}$ & $\begin{array}{c}M_{x} \\
{[\mathrm{kGm}]}\end{array}$ & $\begin{array}{c}M_{y} \\
{[\mathrm{kGm}]}\end{array}$ & $\begin{array}{c}M_{z} \\
{[\mathrm{kGm}]}\end{array}$ & $\begin{array}{c}T_{t r} \\
{[\mathrm{kG}]}\end{array}$ \\
\hline \multirow{2}{*}{ Pullup/pushover } & -887 & 531 & -141000 & -147 & 1090 & -10100 & -388 \\
& 477 & 262 & -8370 & 513 & -976 & 5830 & -885 \\
\hline \multirow{2}{*}{ Diving } & 48 & 111 & -12200 & -76 & -137 & -7600 & -489 \\
& -945 & 337 & -6660 & 310 & 1230 & -3750 & -225 \\
\hline \multirow{2}{*}{ Ranges of load } & -945 & 111 & -14100 & -147 & -976 & -10100 & -885 \\
changes & $\div$ & $\div$ & $\div$ & $\div$ & $\div$ & $\div$ & $\div$ \\
& 477 & 531 & -6660 & 513 & 1230 & 5830 & -225 \\
\hline
\end{tabular}




\section{References}

1. Bramwell, A.R.S; Taylor, G.; Done, S.; Balmford, D. Bramwell's Helicopter Dynamics, 2nd ed.; Butterworth-Heinemann Linacre House: Oxford, 2001.

2. Mil__M.L.; Nekrasov ${ }_{\llcorner}$A.V.; Braverman, A.S. Helicopters-Calculation and Design Vol. I Aerodynamics, Mashinostroeniye Publishing House: Moscow, 1966.

3. Johnson, W. Helicopter Theory, Dover Publictions Inc.: New York, 1980.

4. Stanislawski, J.; Pattern of Helicopter Rotor Loads and Blade Deformations in Some States of Flight Envelope. Transactions of the Institute of Aviation 2015, No. 1(238), pp. 70-90, Warsaw, ISSN 0509-6669.

5. Stanislawski, J.; A Comparison Of Helicopter Main Rotor Features Due to Stiffness of Rotor Blade-Hub Connection. Transactions of the Institute of Aviation 2018, 1 (250) 2018, pp. 119-136.

6. Dayhoum, A.; Zakaria M.Y.; Elshabka A.M.; Abdelhamid O. E. Speculation of local aerodynamic loads on helicopter rotor blade in forward flight. In Proceedings of the 18th International Conference on Aerospace Sciences \& Aviation Technology, IOP Conf. Series: Materials Science and Engineering 610 (2019) 012099, doi:10.1088/1757-899X/610/1/012099

7. Kim, K.C.; Analytical Calculation of Helicopter Main Rotor Blade Flight Loads in Hover and Forward Flight, Technical Report ARL-TR-3180, April 2004.

8. Maksimovic, S.; Kozic, M.; Stetic-Kozic, S.; Maksimovic, K.; Vasovic, I.; Maksimovic M. Determination of Load Distributions on Main Helicopter Rotor Blades and Strength Analysis of Its Structural Components. Journal of Aerospace Engineering 2014 Volume 27, Issue 6.

9. Gupta, S.K. Aerodynamic Loading of the Blades of a Helicopter Rotor in Steady Translational Flight. Ph.D. Thesis, Hamilton, Ontario, Canada, Location of University, 1972.

10. Miller, R.H. Unsteady Air Loads on Helicopter Rotor Blades. Journal of The Royal Aeronautical Society 1964 Vol. 68 , No. 640. pp.217-229

11. Liva, J. Unsteady Air Loads and Stall Effects on Helicopter Rotor Blade Airfoil Sections. In Proceedings of the AIAA 6th Aerospace Sciences Meeting, New York, 22-24 January 1968.

12. Reddy, MVR. Aerodynamic Load Estimation of Helicopter Rotor in Hovering Flight. Journal of Aeronautics \& Aerospace Engineering 2016, Vol. 5, Is. 1, DOI: 10.4172/2168-9792.1000160

13. Beno, E.A.; Analysis of Helicopter Maneuver-Loads and Rotor-Loads Flight-Test Data, Contractor Report NASA CR-2225, 1973.

14. Kowaleczko, G. Analysis of the Dynamics of Spatial Helicopter Motion Taking into Account Autopilot. Ph.D. Thesis, Military University of Technology, Warsaw, Poland, 1992.

15. Kowaleczko, G. Nonlinear Dynamics of Helicopter Spatial Motion. D.Sc. Thesis, Military University of Technology, Warsaw, Poland, 1998.

16. Kowaleczko, G.; Dzygadlo, Z. Nonlinear Regular and Chaotic Dynamics of a Helicopter. Journal of Technical Physics 2001, 42(2), pp. 241-268.

17. Kowaleczko, G. Simulated and Experimental Investigation of The Nap-of-the-Earth Manoeuvers for a Helicopter. In Proceedings of the 26th European Rotorcraft Forum, Hague, Holland, 2000.

18. Kowaleczko, G. An Improved Numerical Approach for Inverse Simulations of Aircraft Manoeuvres. Journal of Theoretical and Applied Mechanics (Poland) 2001, 39, pp. 65-78.

19. Kowaleczko, G. The Inverse Problem in the Dynamics of Aircraft Flight, Publisher: Military University of Technology, 2003; ISBN 83-89399-30-X.

20. Kowaleczko, G.; Dzygadlo, Z. Ground Resonance of a Helicopter. Journal of Theoretical and Applied Mechanics (Poland) 2000, 38, pp. 65-91.

21. Kowaleczko, G.; Dzygadlo, Z. Nonlinear, Regular and Chaotic Flutter of a Helicopter. In Proceedings of the 26th European Rotorcraft Forum, Hague, Holland, 2000.

22. Kowaleczko, G.; Dzygadlo, Z.; Sobieraj, W. The Effect of Some Kinds of Blade Failures on Helicopter Flight Dynamics. . In Proceedings of the 41st Aerospace Sciences Meeting and Exhibit, 2003.

23. Mi-24W Helicopter. Instructions for Use and Piloting Technique. Air Force Command. Poznan, Poland, 1990.

24. Mi-24D Helicopter. Airframe-Technical Description. Air Force Command. Poznan, Poland, 1981.

25. Mi-24 Helicopter. Technical Description-Flight and Technical Characteristics. Air Force Command. Poznan, Poland, 1980.

26. Mi-24A and Mi-24D Helicopters-Practical Aerodynamics. Air Force Command. Poznan, Poland, 1980.

27. Franklin D.H.; Tarzanin F.J.; Fisher R. K. Rotor High-Speed Performance, Theory vs. Test. Journal of American Helicopter Society 1970, 15, Doi: 10.4050/JAHS.15.35.

28. Tarzanin F.J. Prediction of Control Loads Due to Blade Stall. Journal of American Helicopter Society 1972, 17(2), Doi: 10.4050/jahs.17.33. 